\title{
Clinical disease activity and acute phase reactant levels are discordant among patients with active rheumatoid arthritis: acute phase reactant levels contribute separately to predicting outcome at one year
}

Jonathan Kay ${ }^{1 *}$, Olga Morgacheva ${ }^{2}$, Susan P Messing ${ }^{3}$, Joel M Kremer ${ }^{4}$, Jeffrey D Greenberg ${ }^{5}$, George W Reed ${ }^{6}$, Ellen M Gravallese ${ }^{1}$ and Daniel E Furst ${ }^{2}$

\begin{abstract}
Introduction: Clinical trials of new treatments for rheumatoid arthritis (RA) typically require subjects to have an elevated acute phase reactant (APR), in addition to tender and swollen joints. However, despite the elevation of individual components of the Clinical Disease Activity Index (CDAI) (tender and swollen joint counts and patient and physician global assessment), some patients with active RA may have normal erythrocyte sedimentation rate (ESR) and/or C-reactive protein (CRP) levels and thus fail to meet entry criteria for clinical trials. We assessed the relationship between CDAI and APRs in the Consortium of Rheumatology Researchers of North America (CORRONA) registry by comparing baseline characteristics and one-year clinical outcomes of patients with active RA, grouped by baseline APR levels.
\end{abstract}

Methods: This was an observational study of 9,135 RA patients who had both ESR and CRP drawn and a visit at which CDAl was $>2.8$ (not in remission).

Results: Of 9,135 patients with active RA, 58\% had neither elevated ESR nor CRP; only 16\% had both elevated ESR and CRP and 26\% had either ESR or CRP elevated. Among the 4,228 patients who had a one-year follow-up visit, both baseline and one-year follow-up modified Health Assessment Questionnaire (mHAQ) and CDAl scores were lowest for patients with active RA but with neither APR elevated; both mHAQ and CDAl scores increased sequentially with the increase in number of elevated APR levels at baseline. Each individual component of the CDAI followed the same trend, both at baseline and at one-year follow-up. The magnitude of improvement in both CDAI and MHAQ scores at one year was associated positively with the number of APRs elevated at baseline.

Conclusions: In a large United States registry of RA patients, APR levels often do not correlate with disease activity as measured by joint counts and global assessments. These data strongly suggest that it is appropriate to obtain both ESR and CRP from RA patients at the initial visit. Requiring an elevation in APR levels as a criterion for inclusion of RA patients in studies of experimental agents may exclude some patients with active disease.

\footnotetext{
* Correspondence: jonathan.kay@umassmemorial.org

'Division of Rheumatology, Department of Medicine, University of Massachusetts Medical School and UMass Memorial Medical Center, 119 Belmont Street, Worcester, MA 01605, USA

Full list of author information is available at the end of the article
} 


\section{Introduction}

Among patients with rheumatoid arthritis (RA), disease progression over time is difficult to predict. Demographic, clinical, laboratory, and imaging parameters, both alone and in combination, have been used to predict outcomes. In some studies, erythrocyte sedimentation rate (ESR) elevation correlated with disease outcomes such as joint erosion [1-4] and Health Assessment Questionnaire Disability Index (HAQ-DI) scores [5] whereas, in others, increased C-reactive protein (CRP) levels ( $>20 \mathrm{mg} / \mathrm{L}$ ) correlated better with radiographic [6-10] and functional [9,11] outcomes. However, when acute phase reactants (APRs) are discordant, with elevation of only one (ESR or CRP), these laboratory test results may not predict progression of structural damage to joints [12]. Combining clinical measures with an APR level into composite disease activity indices, such as the Disease Activity Score (DAS) 28 or the Simplified Disease Activity Index (SDAI), often predicts structural and functional consequences [3,10,13-15]. However, joint destruction may continue to progress and functional status may still deteriorate in RA patients treated with nonbiologic disease-modifying antirheumatic drugs (DMARDs), despite both improvement in clinical parameters and persistent reduction of the ESR [12,16].

Clinical trials of new treatments for RA typically require subjects to have an elevated acute phase reactant, in addition to tender and swollen joints. However, despite the elevation of individual components of the Clinical Disease Activity Index (CDAI) (tender and swollen joint counts and patient and physician global assessment), some patients with active RA may have normal ESR and/or CRP levels [17-20] and thus fail to meet entry criteria for clinical trials [21].

In this study, we assessed the relationship between CDAI and APRs in the Consortium of Rheumatology Researchers of North America (CORRONA) database, a large United States registry of RA patients. We compared the baseline characteristics and one-year clinical outcomes of patients with active RA, grouped by baseline APR levels.

\section{Subjects and methods Definitions}

The Clinical Disease Activity Index (CDAI) is a simplified disease activity score using a 28 -joint count that integrates measures of physical examination, patient selfassessment, and evaluator assessment. The CDAI score (a scale of 0 to 76.0) is the numerical sum of the 28joint tender and swollen joint counts and the patient and evaluator global health status, each assessed on a $10-\mathrm{cm}$ visual analog scale [22]. It provides a validated indication of RA disease activity, with scores of $\leq 2.8$ signifying remission and scores of $>22$ connoting high disease activity [23]. Because it requires no laboratory test result, the CDAI is easy to calculate and allows for immediate scoring.

The modified Health Assessment Questionnaire (mHAQ) is a simplified version of the Health Assessment Questionnaire (HAQ). The HAQ consists of 20 questions that inquire as to a patient's ability to perform 20 activities of daily living. These questions are grouped into eight categories. The mHAQ consists of eight questions, with one taken from each category of the HAQ [24]. The total mHAQ score is calculated as the mean of the individual scores for each activity [25].

APR levels were considered to be elevated if the ESR was $>28 \mathrm{~mm} / \mathrm{h}$ or if the CRP was $>8 \mathrm{mg} / \mathrm{L}(>0.8 \mathrm{mg} / \mathrm{dL})$.

\section{Subjects}

The CORRONA database from October 1, 2001, through February 27, 2011, was used to identify subjects for this study [26]. Ethical approval for participation in the CORRONA registry was obtained from the respective institutional review boards of participating academic recruitment sites (Bassett Healthcare Network Institutional Review Board, Cooperstown, NY; Baylor Research Institute Institutional Review Board, Dallas, TX; Colorado Multiple Institutional Review Board, Aurora, CO; Geisinger Health Systems Institutional Review Board, Danville, PA; Hospital for Special Surgery Institutional Review Board, New York, NY; Institutional Review Board of the University of Michigan Medical School, Ann Arbor, MI; Johns Hopkins Medicine Institutional Review Board, Baltimore, MD; KUMC Human Subjects Committee, Kansas City, KS; Medical College of Wisconsin/ Froedtert Hospital Institutional Review Board, Milwaukee, WI; Meridian Health Institutional Review Board, Neptune, NJ; Montefiore Medical Center Institutional Review Board, Bronx, NY; North Shore-Long Island Jewish Institutional Review Board, Great Neck, NY; Northwestern University Institutional Review Board, Chicago, IL; NYU School of Medicine Institutional Review Board, New York, NY; Ochsner Institutional Review Board, New Orleans, LA; Rhode Island Hospital Institutional Review Board, Providence, RI; Saint Louis University Institutional Review Board, St. Louis, MO; Southern New Hampshire Medical Center Institutional Review Board, Nashua, NH; SUNY Downstate Institutional Review Board, Brooklyn, NY; UAB Institutional Review Board for Human Use, Birmingham, AL; University of California, Los Angeles Institutional Review Board, Los Angeles, CA; University of California, San Diego Institutional Review Board, San Diego, CA; University of Maryland, Baltimore Institutional Review Board, Baltimore, MD; University of Massachusetts Medical School Committee for the Protection of Human Subjects in Research, Worcester, MA; University of Rochester Research Subjects Review Board, Rochester, NY; University of Wisconsin-Madison Health Sciences Institutional 
Review Board, Madison, WI; UT Southwestern Institutional Review Board, Dallas, TX; Washington University in St. Louis Institutional Review Board, St. Louis, MO) and from the New England Institutional Review Board (Newton, MA), a central institutional review board, for communitybased private recruitment sites. All patients provided written informed consent prior to enrollment in the cohort, which allowed all subsequent analyses of the anonymized data.

Patients were eligible for inclusion if they had a rheumatologist-confirmed diagnosis of RA, but not of psoriatic arthritis (PsA), and a visit with CDAI $>2.8$ (not in remission) and both an ESR and CRP drawn at the visit. A patient's first visit in the CORRONA database with CDAI $>2.8$ and reported APR information was selected as the baseline visit. The CORRONA registry does not mandate measurement of either APR, but records the results of all laboratory studies ordered in the course of routine clinical care. The baseline visit could be either the enrollment visit into the CORRONA database or a follow-up visit. Drug initiation was not a criterion. A one-year follow-up visit was defined as a visit occurring $365 \pm 60$ days after the study baseline visit with both the mHAQ and CDAI measured.

A sensitivity analysis was performed in the subset of biologic-naive RA patients, defined as those patients who had not yet used any biologic agent before or at the time of the baseline visit.

\section{Statistical methods}

Comparisons of outcomes among APR groups (neither (zero) APR elevated, discordant APR levels (one APR elevated), or both (two) APR elevated) were assessed using linear regression models for most continuous outcomes. Log-linear models were used as noted in the tables for outcomes with distributional properties less appropriate for linear regression. Logistic regression models were used for comparison of binary outcomes. In all cases $P$ values were generated using robust variance estimators (sandwich estimators), which provide a method that is not unduly affected by outliers or other small departures from model assumptions. Comparisons of CDAI category distributions were carried out using $\chi^{2}$ tests. No adjustments were made for multiple comparisons. All statistical analyses were carried out using SAS 9.3 on a Windows 7 platform (SAS Institute Inc., Cary, NC, USA).

\section{Results}

\section{Baseline characteristics}

As of February 27, 2011, 27,412 patients with RA were enrolled in the CORRONA registry. Of these, 9,135 patients had a visit with active RA (CDAI >2.8) and had values recorded for both ESR and CRP and thus were eligible for sample inclusion. Of the patients with active RA, 5,295 (58.0\%) had neither elevated ESR nor CRP. Only 1,507 (16.5\%) had elevated levels of both ESR and CRP. Among the remaining 25.5\% of patients, levels of ESR and CRP were discordant: 1,212 (13.3\%) had an elevated ESR, but not CRP, and 1,121 (12.3\%) had an elevated CRP, but not ESR (Figure $1 \mathrm{~A}$ ).

Among the 9,135 patients, 4,031 (44.1\%) were biologicnaïve. The distribution of APR levels in this subset of biologic-naïve patients was similar to that in the entire group of 9,135 patients with active RA. Of the biologicnaïve patients with active RA, 2,164 (53.7\%) had neither elevated ESR nor CRP. Only 765 (19.0\%) had elevated levels of both ESR and CRP. Among the remaining 27.3\% of patients, levels of ESR and CRP were discordant: 510 (12.6\%) had an elevated ESR, but not CRP, and 592 (14.7\%) had an elevated CRP, but not ESR (Figure 1B).

Of the 9,135 patients who were eligible for sample inclusion, 4,228 patients had a study visit in the 60-day window of the one-year follow-up visit. The distribution of APR levels at baseline, in this subset of patients with one-year follow-up, was also similar to that in the entire group of 9,135 patients with active RA. Of the patients with active RA and a one-year follow-up visit, 2,520 (59.6\%) had neither elevated ESR nor CRP. Only 650 (15.4\%) had elevated levels of both ESR and CRP. Among the remaining $25.0 \%$ of patients, levels of ESR and CRP were discordant: 557 (13.2\%) had an elevated ESR, but not CRP, and 501 (11.8\%) had elevated CRP, but not ESR. For subsequent analyses, the 1,058 patients with discordant APR levels (ESR $>28 \mathrm{~mm} / \mathrm{h}$ but CRP $\leq 8 \mathrm{mg} / \mathrm{L}$ or CRP $>8 \mathrm{mg} / \mathrm{L}$ but ESR $\leq 28 \mathrm{~mm} / \mathrm{h}$ ) were combined into a single group (Figure 2).

The baseline mHAQ and CDAI scores were lowest for patients with active RA but with neither APR elevated (Table 1). Both mHAQ and CDAI scores increased sequentially as the number of elevated APR levels increased (neither APR elevated, discordant APR levels, or both APR elevated) at baseline. Each individual component of the CDAI followed the same trend. Methotrexate (MTX) use did not differ between groups. As the number of elevated baseline APRs increased, the proportion of patients taking prednisone also increased (even after adjustment for age). These trends were also observed among the subset of biologic-naïve patients with active RA (Table 2). In contrast to prednisone use, among all 9,135 patients with active RA, the proportion of patients using biologics decreased with increasing number of elevated baseline APRs (Table 1).

Distribution of disease activity levels at baseline was significantly different $(P<0.001)$ among the APR groups (Figure 3). Patients with both APRs elevated had a 36.8\% rate of CDAI high disease activity, contrasted with $23.5 \%$ in those with discordant APR levels and $16.7 \%$ in those 


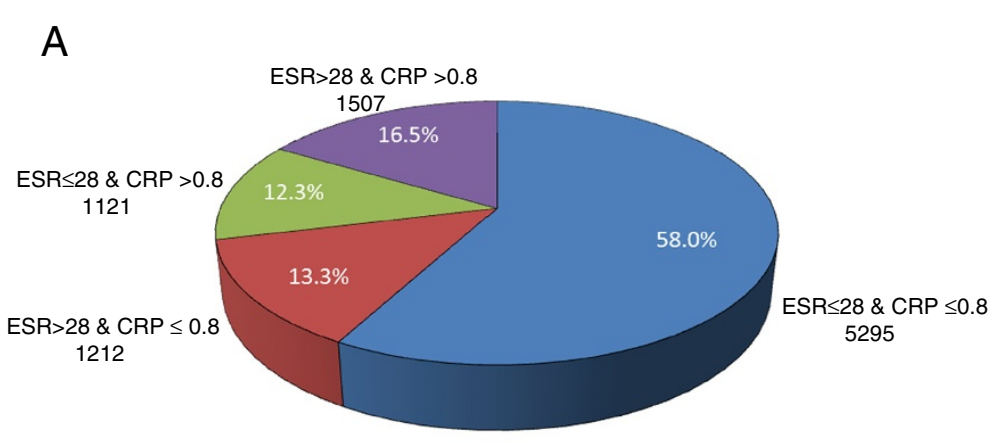

B

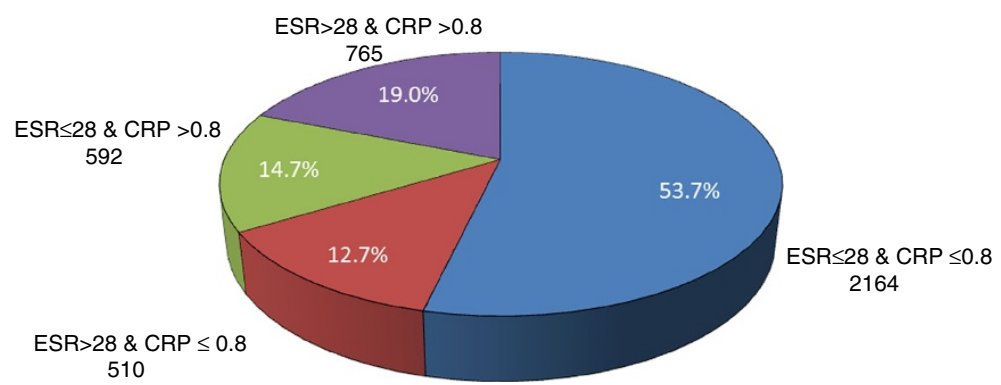

Figure 1 Distribution of acute phase reactant levels at baseline. Distribution of ESR and CRP levels at baseline (A) among the 9,135 patients who had a visit with active RA (CDAI >2.8), and (B) among the 4,031 biologic-naiive patients who had a visit with active RA (CDAl >2.8). CDAl, Clinical Disease Activity Index; CRP, C-reactive protein; ESR, erythrocyte sedimentation rate; RA, rheumatoid arthritis.

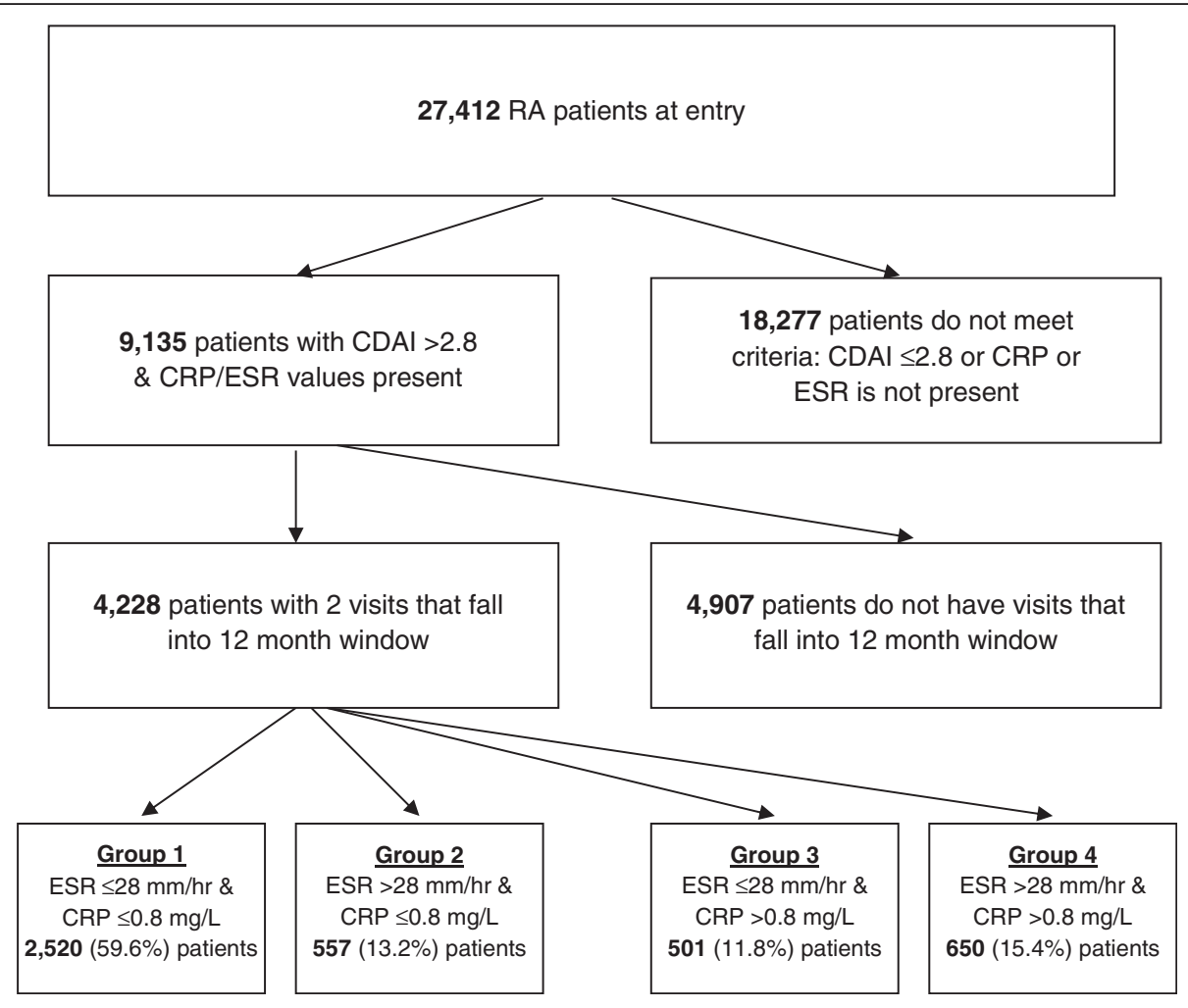

Figure 2 Flow chart showing the distribution of study patients. 
Table 1 Baseline characteristics by APR levels

\begin{tabular}{|c|c|c|c|c|}
\hline & $\begin{array}{l}\text { Neither APR elevated } \\
\qquad n=2,520\end{array}$ & $\begin{array}{l}\text { APR levels discordant } \\
\qquad n=1,058\end{array}$ & $\begin{array}{l}\text { Both APR elevated } \\
\qquad n=650\end{array}$ & $P$ value \\
\hline Age (years) & $59.29 \pm 13.22$ & $62.21 \pm 13.21$ & $62.71 \pm 13.34$ & $<0.0001$ \\
\hline Duration of RA (years) & $11.01 \pm 9.83$ & $11.93 \pm 10.68$ & $10.91 \pm 10.27$ & 0.0406 \\
\hline One-year follow-up duration (days) & $362.63 \pm 30.51$ & $363.33 \pm 31.06$ & $363.46 \pm 32.03$ & 0.7410 \\
\hline $\mathrm{mHAQ}$ & $0.33 \pm 0.40$ & $0.45 \pm 0.47$ & $0.56 \pm 0.54$ & $<0.0001$ \\
\hline CDAl & $12.89 \pm 10.15$ & $15.18 \pm 11.16$ & $20.47 \pm 14.68$ & $<0.0001$ \\
\hline Tender joints & $3.73 \pm 5.24$ & $4.29 \pm 5.40$ & $6.30 \pm 7.21$ & $<0.0001^{*}$ \\
\hline Swollen joints & $4.04 \pm 5.13$ & $4.80 \pm 5.49$ & $6.64 \pm 6.42$ & $<0.0001^{*}$ \\
\hline Patient global assessment & $30.91 \pm 23.82$ & $36.35 \pm 25.45$ & $42.90 \pm 27.56$ & $<0.0001$ \\
\hline MD global assessment & $20.21 \pm 16.61$ & $24.67 \pm 19.06$ & $32.42 \pm 22.50$ & $<0.0001$ \\
\hline Prednisone use & $680(26.98 \%)$ & $341(32.23 \%)$ & $275(42.31 \%)$ & $<0.0001$ \\
\hline Methotrexate use & $1,668(66.19 \%)$ & $698(65.97 \%)$ & $417(64.15 \%)$ & 0.6166 \\
\hline Biologic use & $1,263(50.12 \%)$ & $447(42.25 \%)$ & $224(34.46 \%)$ & $<0.0001$ \\
\hline
\end{tabular}

"Log-linear model (Poisson) - $x^{2}$ test. APR, acute phase reactant; RA, rheumatoid arthritis; mHAQ, modified Health Assessment Questionnaire; CDAl, Clinical Disease Activity Index.

with neither APR elevated. Rates of moderate disease activity were similar among APR groups $(32.8 \%$ for both APR elevated, $33.8 \%$ for discordant APR levels, and $30.2 \%$ for neither APR elevated), but rates of CDAI low disease activity differed (30.5\% for both APR elevated versus $42.6 \%$ for discordant APR levels, and 53.1\% for neither APR elevated). Disease activity levels at baseline were distributed similarly among the APR groups in the subset of biologic-naïve patients with active RA (data not shown).

\section{One-year follow-up}

The mean mHAQ score at one-year follow-up was lowest for patients with active RA and neither APR elevated and was highest for those with both APRs elevated (Tables 3 and 4). Likewise, the mean CDAI score at one-year followup was lowest for those patients with neither APR elevated and was highest for those with both APRs elevated.

There was a positive association between the magnitude of improvement in both CDAI and mHAQ scores at one year and the number of APRs elevated at baseline. The mean mHAQ score $( \pm$ SD) decreased by $0.10 \pm 0.43$ for those with both APRs elevated at baseline, but did not change for those patients with neither APR elevated at baseline (Table 5). The mean CDAI score $( \pm$ SD) decreased by $7.68 \pm 14.19$ for those patients with both APRs elevated, by $3.92 \pm 12.37$ for those with discordant APR levels, and by only $2.40 \pm 10.87$ for those with neither APR elevated (Table 5). A similar trend was observed for each of the individual components of the CDAI, each of which

Table 2 Baseline characteristics of biologic-naïve patients by APR levels

\begin{tabular}{|c|c|c|c|c|}
\hline & $\begin{array}{l}\text { Neither APR elevated } \\
\qquad n=1,012\end{array}$ & $\begin{array}{l}\text { APR levels discordant } \\
\qquad n=487\end{array}$ & $\begin{array}{l}\text { Both APR elevated } \\
\qquad n=324\end{array}$ & $P$ value \\
\hline Age (years) & $60.92 \pm 13.49$ & $63.24 \pm 13.51$ & $64.26 \pm 12.79$ & $<0.0001$ \\
\hline Duration of RA (years) & $8.62 \pm 9.37$ & $9.55 \pm 10.46$ & $7.47 \pm 8.38$ & 0.0074 \\
\hline One-year follow-up duration (days) & $363.43 \pm 29.79$ & $364.78 \pm 31.48$ & $365.43 \pm 31.72$ & 0.5196 \\
\hline $\mathrm{mHAQ}$ & $0.29 \pm 0.38$ & $0.38 \pm 0.43$ & $0.48 \pm 0.53$ & $<0.0001$ \\
\hline CDAl & $12.54 \pm 10.18$ & $14.61 \pm 11.21$ & $19.04 \pm 14.91$ & $<0.0001$ \\
\hline Tender joints & $3.53 \pm 5.14$ & $4.10 \pm 5.46$ & $5.68 \pm 6.92$ & $<0.0001^{*}$ \\
\hline Swollen joints & $4.19 \pm 5.41$ & $4.76 \pm 5.53$ & $6.92 \pm 6.73$ & $<0.0001^{*}$ \\
\hline Patient global assessment & $28.47 \pm 23.70$ & $34.31 \pm 25.08$ & $39.04 \pm 27.26$ & $<0.0001$ \\
\hline MD global assessment & $19.73 \pm 15.59$ & $23.22 \pm 18.46$ & $31.20 \pm 23.03$ & $<0.0001$ \\
\hline Prednisone use & $247(24.41 \%)$ & $138(28.34 \%)$ & $124(38.27 \%)$ & $<0.0001$ \\
\hline Methotrexate use & $696(68.77 \%)$ & $322(66.12 \%)$ & 191 (58.95\%) & 0.0050 \\
\hline
\end{tabular}

${ }^{*}$ Log-linear model (Poisson) - $\chi^{2}$ test. APR, acute phase reactant; RA, rheumatoid arthritis; mHAQ, modified Health Assessment Questionnaire; CDAl, Clinical Disease Activity Index. 


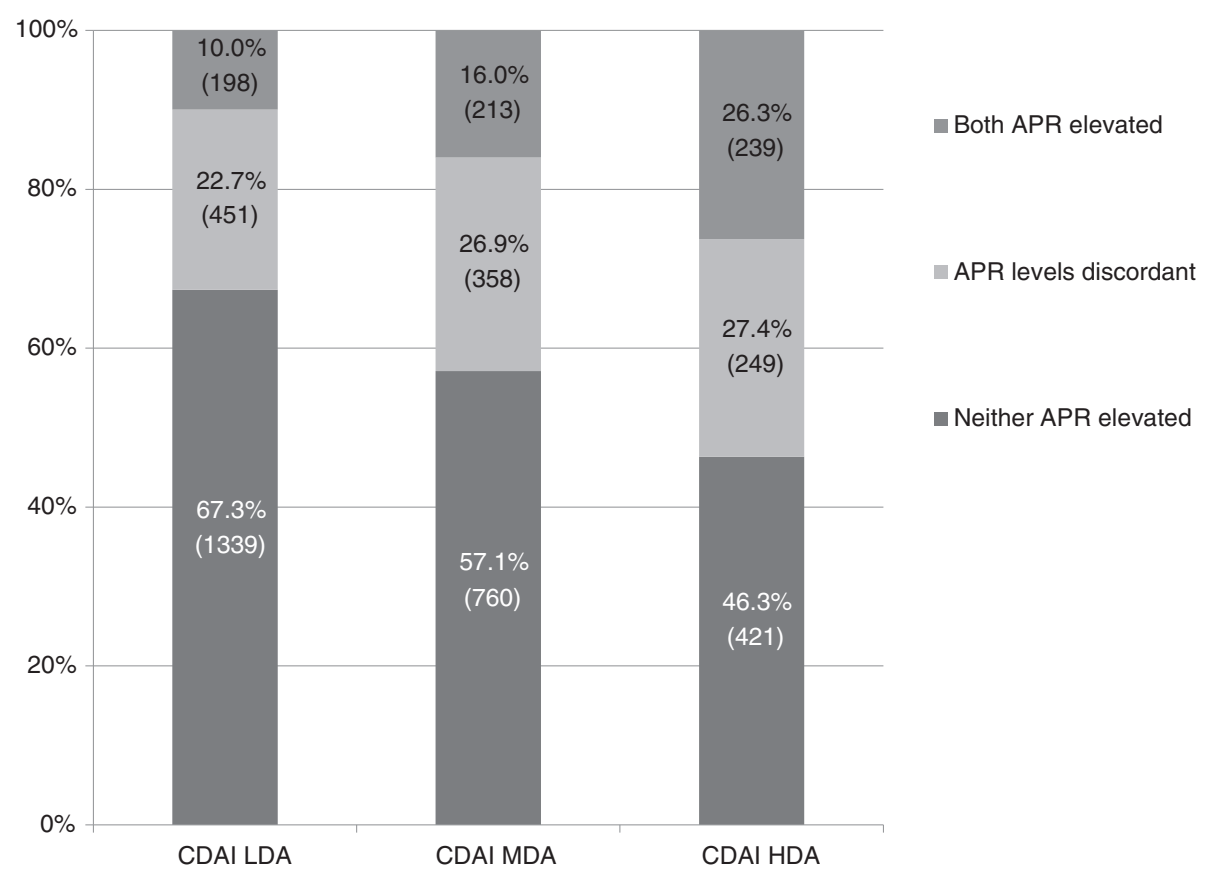

Figure 3 Distribution of acute phase reactant groups among the CDAI disease activity levels at baseline. Distribution of acute phase reactant groups among the CDAl disease activity levels at baseline in the 4,228 RA patients with a one-year follow-up visit. Percentages within the bars indicate relative proportions of subjects within each CDAI disease activity level. Numbers in parentheses within the bars enumerate subjects in each group. CDAl, Clinical Disease Activity Index; RA, rheumatoid arthritis; LDA, low disease activity; MDA, moderate disease activity; HDA, high disease activity.

was statistically significant at $P<0.0001$. The positive association between the magnitude of improvement in both CDAI and mHAQ scores at one year and the number of APRs elevated at baseline was also observed in the subset of biologic-naïve RA patients, as was the similar trend for each of the individual components of the CDAI (Table 6).

\section{Discussion}

In this study, we examined the relationship between APRs and clinical outcome measures in patients with active RA. The traditional expectation is that RA patients with CDAI high disease activity might be more likely to have levels of both APRs elevated, whereas those with CDAI low disease activity might not have elevation of either APR. However, both APRs were elevated in only $26.3 \%$ of patients with CDAI high disease activity in our cohort, whereas neither APR was elevated in 46.3\%; conversely, $32.7 \%$ of those with CDAI low disease activity had at least one APR elevated and $10.0 \%$ had both APRs elevated (Figure 3). These findings imply that APR levels, which traditionally are measured in most randomized clinical trials, often do not reflect disease activity as measured by joint counts and global assessments. When only one APR was assessed at the initial evaluation, we observed that an elevated level might not be detected in up to $73.7 \%$ (670) of the patients with high CDAIs and up to $84.0 \%(1,118)$ of those with moderate CDAIs. We have thus determined that the yield

Table 3 Clinical and functional status at one-year follow-up by APR levels

\begin{tabular}{|c|c|c|c|c|}
\hline & $\begin{array}{l}\text { Neither APR elevated } \\
\qquad n=2,520\end{array}$ & $\begin{array}{l}\text { APR levels discordant } \\
\qquad n=1,058\end{array}$ & $\begin{array}{l}\text { Both APR elevated } \\
\qquad n=650\end{array}$ & $P$ value \\
\hline $\mathrm{mHAQ}$ & $0.34 \pm 0.42$ & $0.42 \pm 0.49$ & $0.47 \pm 0.54$ & $<0.0001$ \\
\hline CDAl & $10.45 \pm 10.74$ & $11.34 \pm 10.72$ & $12.75 \pm 11.87$ & $<0.0001$ \\
\hline Tender joints & $3.04 \pm 5.36$ & $3.01 \pm 4.88$ & $3.55 \pm 5.87$ & $0.1125^{*}$ \\
\hline Swollen joints & $2.93 \pm 4.65$ & $3.31 \pm 4.72$ & $4.03 \pm 5.27$ & $<0.0001^{*}$ \\
\hline Patient global assessment & $28.50 \pm 24.81$ & $31.53 \pm 26.13$ & $31.74 \pm 26.68$ & $<0.0007$ \\
\hline MD global assessment & $16.02 \pm 16.31$ & $18.23 \pm 17.19$ & $19.73 \pm 19.73$ & $<0.0001$ \\
\hline
\end{tabular}

${ }^{\overline{ }}$ Log-linear model (Poisson) $-x^{2}$ test. APR, acute phase reactant; mHAQ, modified Health Assessment Questionnaire; CDAl, Clinical Disease Activity Index. 
Table 4 Clinical and functional status at one-year follow-up by APR levels among biologic-naïve patients

\begin{tabular}{|c|c|c|c|c|}
\hline & $\begin{array}{l}\text { Neither APR elevated } \\
\qquad n=1,012\end{array}$ & $\begin{array}{l}\text { APR levels discordant } \\
\qquad n=487\end{array}$ & $\begin{array}{l}\text { Both APR elevated } \\
\qquad n=324\end{array}$ & $P$ value \\
\hline $\mathrm{mHAQ}$ & $0.28 \pm 0.40$ & $0.32 \pm 0.43$ & $0.34 \pm 0.46$ & 0.0623 \\
\hline CDAl & $9.65 \pm 10.11$ & $9.75 \pm 9.81$ & $10.85 \pm 11.17$ & 0.2243 \\
\hline Tender joints & $2.64 \pm 4.93$ & $2.41 \pm 4.33$ & $2.83 \pm 5.17$ & $0.4378^{*}$ \\
\hline Swollen joints & $2.90 \pm 4.66$ & $2.91 \pm 4.54$ & $3.52 \pm 5.04$ & $0.1299^{*}$ \\
\hline Patient global assessment & $26.23 \pm 24.77$ & $28.36 \pm 25.62$ & $28.68 \pm 26.53$ & 0.1149 \\
\hline MD global assessment & $14.52 \pm 14.82$ & $15.61 \pm 15.38$ & $16.43 \pm 15.85$ & $<0.0001$ \\
\hline Biologic use & 150 (14.84\%) & $83(17.08 \%)$ & 67 (20.68\%) & 0.0437 \\
\hline
\end{tabular}

"Log-linear model (Poisson) - $\chi^{2}$ test. APR, acute phase reactant; mHAQ, modified Health Assessment Questionnaire; CDAl, Clinical Disease Activity Index.

of identifying an elevated APR in patients with active RA is greater when both the ESR and CRP are obtained at the baseline evaluation.

Discordance between APRs has also been observed in other studies that correlated clinical characteristics with laboratory findings $[17,19,20]$. Graf and colleagues found a weak correlation between CRP levels and CDAI scores $(\mathrm{r}=0.18, P=0.027)$ among 151 patients with RA [19]. Although all seven of their patients who were in CDAI remission had CRP $<8 \mathrm{mg} / \mathrm{L}$, only $46(33.3 \%)$ of the 138 patients with CDAI $>2.8$ had CRP $>8 \mathrm{mg} / \mathrm{L}$. Crowson and coworkers also found a weak correlation between APRs and CDAI scores $(r=0.29$ for CRP and $r=0.28$ for ESR) among 1,247 RA patients [17]. DAS28, which includes an APR in its scoring, correlated more closely with APRs, ( $r=0.48$ for CRP and $r=0.53$ for ESR), as expected. In another study of 689 patients with RA, Wolfe and collaborators found $41 \%$ agreement between DAS28 and ESR (Kendall's tau-a 0.41; 95\% CI: 0.37 to 0.45) [20].

In our cohort of patients with active RA, as defined by CDAI $>2.8$, the number of elevated APRs $(0,1$, or 2$)$ often did not reflect disease activity at the time of the baseline measure: $46.3 \%$ had neither APR elevated with a high CDAI and 32.7\% had elevation of at least one APR, despite being in a CDAI low disease activity state (Figure 3 ). Both APRs were elevated in only $26.3 \%$ of those with high baseline CDAIs. Crowson and coworkers also observed a poor correlation between the number of swollen joints and APR elevation [17]. Discordance between clinical parameters and laboratory values may be due, at least in part, to the lower sensitivity of detecting subtle joint inflammation during the clinical examination of patients with RA [27]. APR elevation may also reflect inflammation in areas other than the joints [28]. Thus, in many RA patients, APR values alone may not be accurate indicators of disease activity.

We observed an association between the numbers of APR elevated at baseline and the CDAI or mHAQ response at one year. The greatest decrease in CDAI was observed when both APRs were elevated at baseline and the smallest when neither APR was elevated. An intermediate decrease was observed when APR levels were discordant. Similar 'APR-dependent' associations were found between each of the individual components of CDAI, except for the tender joint count (Tables 5 and 6). The number of tender joints can be influenced by factors other than joint inflammation, including osteoarthritis of the examined joints or pain amplification in central sensitization syndromes, thereby rendering it less reflective of RA disease activity [29]. The change in mHAQ score also correlated with the number of APRs elevated at baseline, although less consistently than did the change in CDAI score (Tables 5 and 6).

As expected, there was an inverse relationship between APRs and the use of biologics. However, there was a direct relationship between APRs and the use of prednisone: the greatest proportion of patients using prednisone was in the group of patients with both APRs elevated.

Table 5 Change in clinical and functional status between baseline and one year by APR levels

\begin{tabular}{|c|c|c|c|c|}
\hline & $\begin{array}{l}\text { Neither APR elevated } \\
\qquad n=2,520\end{array}$ & $\begin{array}{l}\text { APR levels discordant } \\
\qquad n=1,058\end{array}$ & $\begin{array}{l}\text { Both APR elevated } \\
\qquad n=650\end{array}$ & $P$ value \\
\hline $\mathrm{mHAQ}$ & $0.01 \pm 0.31$ & $-0.03 \pm 0.40$ & $-0.10 \pm 0.43$ & $<0.0001$ \\
\hline CDAl & $-2.40 \pm 10.87$ & $-3.92 \pm 12.37$ & $-7.68 \pm 14.19$ & $<0.0001$ \\
\hline Tender joints & $-0.69 \pm 5.48$ & $-1.28 \pm 5.81$ & $-2.75 \pm 6.98$ & $<0.0001$ \\
\hline Swollen joints & $-1.12 \pm 5.11$ & $-1.49 \pm 5.53$ & $-2.58 \pm 5.95$ & $<0.0001$ \\
\hline Patient global assessment & $-2.38 \pm 25.21$ & $-4.90 \pm 27.78$ & $-11.29 \pm 30.11$ & $<0.0001$ \\
\hline MD global assessment & $-4.21 \pm 17.30$ & $-6.45 \pm 19.78$ & $-12.57 \pm 23.19$ & $<0.0001$ \\
\hline
\end{tabular}

APR, acute phase reactant; mHAQ, modified Health Assessment Questionnaire; CDAl, Clinical Disease Activity Index. 
Table 6 Change in clinical and functional status between baseline and one year by APR levels among biologic-naïve patients

\begin{tabular}{|c|c|c|c|c|}
\hline & $\begin{array}{l}\text { Neither APR elevated } \\
\qquad n=1,012\end{array}$ & $\begin{array}{l}\text { APR levels discordant } \\
\qquad n=487\end{array}$ & $\begin{array}{l}\text { Both APR elevated } \\
\qquad n=324\end{array}$ & $P$ value \\
\hline $\mathrm{mHAQ}$ & $0.00 \pm 0.29$ & $-0.06 \pm 0.35$ & $-0.14 \pm 0.41$ & $<0.0001$ \\
\hline CDAl & $-2.91 \pm 10.92$ & $-4.93 \pm 12.35$ & $-8.16 \pm 13.53$ & $<0.0001$ \\
\hline Tender joints & $-0.91 \pm 5.54$ & $-1.69 \pm 5.88$ & $-2.82 \pm 6.64$ & $<0.0001$ \\
\hline Swollen joints & $-1.28 \pm 5.11$ & $-1.85 \pm 5.60$ & $-2.81 \pm 5.78$ & $<0.0001$ \\
\hline Patient global assessment & $-2.14 \pm 26.41$ & $-6.00 \pm 27.96$ & $-10.58 \pm 30.18$ & $<0.0001$ \\
\hline MD global assessment & $-5.23 \pm 16.46$ & $-7.62 \pm 19.49$ & $-14.62 \pm 22.91$ & $<0.0001$ \\
\hline
\end{tabular}

APR, acute phase reactant; $\mathrm{mHAQ}$, modified Health Assessment Questionnaire; CDAl, Clinical Disease Activity Index.

Thus, the relationships of APRs to the use of prednisone and to the use of biologics move in opposite directions. This may reflect both the effectiveness of biologics in reducing APR levels and the propensity of physicians to use corticosteroids to treat patients with active RA. No difference was observed among patients taking MTX, consistent with the previously reported weak effect of MTX on APRs [30,31].

This was an observational study of data from a registry, in which clinical measurements were mandated but laboratory studies were not and were ordered according to physician practice style. Thus, not all patients in the CORRONA database had values available for both ESR and CRP. However, the demographic characteristics of the patients who did not have either APR measured were similar to those for whom an ESR or CRP level had been obtained. Among 92,062 visits for 17,445 RA patients in the CORRONA database, an APR was measured at 47,164 (51.2\%) of the visits. There was no association between whether or not an APR level had been assessed and age, sex, or measures of disease activity or physical function [32].

For our study, we chose cutoff values of $28 \mathrm{~mm} / \mathrm{h}$ for ESR and $8 \mathrm{mg} / \mathrm{L}$ for CRP in patients with active RA, since these APR values have typically been used as entry criteria for clinical trials of novel therapies for RA. However, the cutoff value for the ESR is above the upper limit of normal used by clinical laboratories for this test. Moreover, in clinical practice, rheumatologists prefer to see APR levels well below the upper limit of normal when treating patients with RA. Thus, the proportion of patients with 'normal' levels of both APR might have been smaller if a lower cutoff value for the ESR had been used. However, our finding that disease activity measures correlate weakly with APR elevation underscores the limitations of using minimum values of $28 \mathrm{~mm} / \mathrm{h}$ for ESR or $8 \mathrm{mg} / \mathrm{L}$ for CRP, in addition to swollen and tender joint counts, as entry criteria for clinical trials of novel therapies for RA, since the majority of patients with active RA have levels of both ESR and CRP below these threshold values. In addition, there was a possible floor effect among patients with fewer APRs elevated at baseline: patients who are doing better have less 'room for improvement' and those who start from a 'worse place' may make greater gains.

For most patients in our study, CDAI was responsive to change and can serve as a good indicator of the degree of joint inflammation. A better understanding of the relationship between APRs and disease activity, as measured by the CDAI, will allow for a more informed use of these measures in clinical practice and in clinical trials of novel therapeutic agents. In addition, our observation that elevation of APR levels is often discordant with what clinicians can measure in the clinic implies that systemic inflammation may continue, even while joint swelling and tenderness are 'controlled'. It is also possible that this systemic inflammation involves areas other than the joints [28].

Normalization of CRP levels in subjects at risk for heart disease is associated with a significantly lower number of cardiovascular events [28]. This same comorbidity is the chief cause of premature mortality in patients with RA [33]. It therefore follows that elucidating the long-term relationship between APRs and cardiovascular disease in patients with RA will add greatly to our understanding of the overall relevance of these measures in clinical domains other than those typically measured in daily practice and in randomized clinical trials in rheumatology. These relationships likely will become clearer with continued observation of these variables among large numbers of patients followed in long-term disease registries.

\section{Conclusions}

Obtaining both ESR and CRP in a patient with active RA increases the yield of identifying an elevated APR level. However, APR levels often do not reflect disease activity, as measured by joint counts and global assessments. Change in CDAI and mHAQ at one year is associated with the number of APRs elevated at baseline.

The normal APR levels present in over half of patients with active joint disease, as determined by CDAI, in a large United States registry of RA patients would exclude 
these patients from participation in many clinical trials of novel therapies for RA. Thus, clinical trials of novel therapies for RA might use CDAI $>10$ (the cutoff for moderate disease activity), rather than elevated APR, as a criterion for entry. These changes might have the effect of increasing enrollment while providing a more representative population of patients for clinical trials. The long-term implications of discordance in APRs will need to be studied further in large populations of RA patients followed prospectively over prolonged time intervals.

\section{Abbreviations}

APR: acute phase reactant; CDAl: Clinical Disease Activity Index; CORRONA: Consortium of Rheumatology Researchers of North America: CRP: C-reactive protein; DAS: Disease Activity Score; DMARD: diseasemodifying antirheumatic drug; ESR: erythrocyte sedimentation rate; HAQ-DI: Health Assessment Questionnaire Disability Index; mHAQ: modified Health Assessment Questionnaire; MTX: methotrexate; RA: rheumatoid arthritis; SDAl: Simplified Disease Activity Index.

\section{Competing interests}

The authors declare that they have no competing interests.

\begin{abstract}
Authors' contributions
JK conceived of the study, participated in its design and coordination and in analysis and interpretation of data, and drafted the manuscript. OM participated in the coordination of the study and helped to draft the manuscript. SPM participated in the design of the study, performed the statistical analysis, and helped to draft the manuscript. JMK and JDG organized and participated in data acquisition and coordination of the study and helped to revise the manuscript critically for important intellectual content. GWR and EMG participated in the analysis and interpretation of data and helped to revise the manuscript critically for important intellectual content. DEF participated in the conception, design and coordination of the study and in analysis and interpretation of data, and helped to draft the manuscript. All authors read and approved the final manuscript.
\end{abstract}

\section{Author details}

'Division of Rheumatology, Department of Medicine, University of Massachusetts Medical School and UMass Memorial Medical Center, 119 Belmont Street, Worcester, MA 01605, USA. ²Division of Rheumatology, Department of Medicine, David Geffen School of Medicine, 10833 Le Conte Avenue, Los Angeles, CA 90095, USA. ${ }^{3}$ Department of Biostatistics and Computational Biology, University of Rochester Medical Center, 601 Elmwood Avenue, Rochester, NY 14642, USA. ${ }^{4}$ Division of Rheumatology, Department of Medicine, Albany Medical College and the Center for Rheumatology, 1367 Washington Avenue, Albany, NY 12203, USA. ${ }^{5}$ Department of Rheumatology, New York University Hospital for Joint Diseases, 301 East 17th Street, New York, NY 10003, USA. ${ }^{6}$ The Consortium of Rheumatology Researchers of North America, Inc. (CORRONA), 10 Vickery Hill Lane, Southborough, MA 01772, USA.

Received: 9 April 2013 Accepted: 24 January 2014

Published: 3 February 2014

\section{References}

1. Scott DL, Grindulis KA, Struthers GR, Coulton BL, Popert AJ, Bacon PA: Progression of radiological changes in rheumatoid arthritis. Ann Rheum Dis 1984, 43:8-17.

2. Möttönen TT: Prediction of erosiveness and rate of development of new erosions in early rheumatoid arthritis. Ann Rheum Dis 1988, 47:648-653.

3. Dixey J, Solymossy C, Young A, Early RAS: Is it possible to predict radiological damage in early rheumatoid arthritis (RA)? A report on the occurrence, progression, and prognostic factors of radiological erosions over the first 3 years in 866 patients from the Early RA Study (ERAS). J Rheumatol Suppl 2004, 69:48-54.
4. Caruso I, Santandrea S, Sarzi Puttini P, Boccassini L, Montrone F, Cazzola M, Azzolini V, Segre D: Clinical, laboratory and radiographic features in early rheumatoid arthritis. J Rheumatol 1990, 17:1263-1267.

5. Wolfe F, Hawley DJ: The longterm outcomes of rheumatoid arthritis: Work disability: a prospective 18 year study of 823 patients. J Rheumatol 1998, 25:2108-2117.

6. van Leeuwen MA, van Rijswijk MH, van der Heijde DM, Te Meerman GJ, van Riel PL, Houtman PM, van De Putte LB, Limburg PC: The acute-phase response in relation to radiographic progression in early rheumatoid arthritis: a prospective study during the first three years of the disease. Br J Rheumatol 1993, 32:9-13.

7. Aman S, Paimela L, Leirisalo-Repo M, Risteli J, Kautiainen H, Helve T, Hakala $M$ : Prediction of disease progression in early rheumatoid arthritis by ICTP, RF and CRP. A comparative 3-year follow-up study. Rheumatology 2000, 39:1009-1013.

8. Plant MJ, Williams AL, O'Sullivan MM, Lewis PA, Coles EC, Jessop JD: Relationship between time-integrated C-reactive protein levels and radiologic progression in patients with rheumatoid arthritis. Arthritis Rheum 2000, 43:1473-1477.

9. Jansen LM, van der Horst-Bruinsma IE, van Schaardenburg D, Bezemer PD, Dijkmans BA: Predictors of radiographic joint damage in patients with early rheumatoid arthritis. Ann Rheum Dis 2001, 60:924-927.

10. Emery P, Gabay C, Kraan M, Gomez-Reino J: Evidence-based review of biologic markers as indicators of disease progression and remission in rheumatoid arthritis. Rheumatol Int 2007, 27:793-806.

11. Jansen LM, van Schaardenburg D, van Der Horst-Bruinsma IE, Bezemer PD, Dijkmans BA: Predictors of functional status in patients with early rheumatoid arthritis. Ann Rheum Dis 2000, 59:223-226.

12. Amos RS, Constable TJ, Crockson RA, Crockson AP, McConkey B: Rheumatoid arthritis: relation of serum C-reactive protein and erythrocyte sedimentation rates to radiographic changes. Br Med J 1977, 1:195-197.

13. Prevoo ML, van't Hof MA, Kuper HH, van Leeuwen MA, van de Putte LB, van Riel PL: Modified disease activity scores that include twenty-eight-joint counts. Development and validation in a prospective longitudinal study of patients with rheumatoid arthritis. Arthritis Rheum 1995, 38:44-48.

14. Devlin J, Gough A, Huissoon A, Perkins P, Holder R, Reece R, Arthur V, Emery $P$ : The acute phase and function in early rheumatoid arthritis. C-reactive protein levels correlate with functional outcome. J Rheumatol 1997, 24:9-13.

15. Wells G, Becker JC, Teng J, Dougados M, Schiff M, Smolen J, Aletaha D, van Riel PL: Validation of the 28-joint Disease Activity Score (DAS28) and European League Against Rheumatism response criteria based on C-reactive protein against disease progression in patients with rheumatoid arthritis, and comparison with the DAS28 based on erythrocyte sedimentation rate. Ann Rheum Dis 2009, 68:954-960.

16. Foltz V, Gandjbakhch F, Etchepare F, Rosenberg C, Tanguy ML, Rozenberg S, Bourgeois P, Fautrel B: Power Doppler ultrasound, but not low-field magnetic resonance imaging, predicts relapse and radiographic disease progression in rheumatoid arthritis patients with low levels of disease activity. Arthritis Rheum 2012, 64:67-76.

17. Crowson CS, Rahman MU, Matteson EL: Which measure of inflammation to use? A comparison of erythrocyte sedimentation rate and C-reactive protein measurements from randomized clinical trials of golimumab in rheumatoid arthritis. J Rheumatol 2009, 36:1606-1610.

18. Gardiner PV, Bell AL, Taggart AJ, Wright G, Kee F, Smyth A, McKane R, Lee J, Rooney ME, Whitehead E: A potential pitfall in the use of the Disease Activity Score (DAS28) as the main response criterion in treatment guidelines for patients with rheumatoid arthritis. Ann Rheum Dis 2005, 64:506-507.

19. Graf J, Scherzer R, Grunfeld C, Imboden J: Levels of C-reactive protein associated with high and very high cardiovascular risk are prevalent in patients with rheumatoid arthritis. PLoS One 2009, 4:e6242.

20. Wolfe F, Michaud K, Pincus T, Furst D, Keystone E: The disease activity score is not suitable as the sole criterion for initiation and evaluation of anti-tumor necrosis factor therapy in the clinic: discordance between assessment measures and limitations in questionnaire use for regulatory purposes. Arthritis Rheum 2005, 52:3873-3879.

21. Sokka T, Pincus T: Eligibility of patients in routine care for major clinical trials of anti-tumor necrosis factor alpha agents in rheumatoid arthritis. Arthritis Rheum 2003, 48:313-318. 
22. Aletaha D, Nell VP, Stamm T, Uffmann M, Pflugbeil S, Machold K, Smolen JS: Acute phase reactants add little to composite disease activity indices for rheumatoid arthritis: validation of a clinical activity score. Arthritis Res Ther 2005, 7:R796-R806.

23. Aletaha D, Smolen J: The Simplified Disease Activity Index (SDAI) and the Clinical Disease Activity Index (CDAl): a review of their usefulness and validity in rheumatoid arthritis. Clin Exp Rheumatol 2005, 23:S100-S108.

24. Fries JF, Spitz P, Kraines RG, Holman HR: Measurement of patient outcome in arthritis. Arthritis Rheum 1980, 23:137-145.

25. Pincus T, Summey JA, Soraci SA Jr, Wallston KA, Hummon NP: Assessment of patient satisfaction in activities of daily living using a modified Stanford Health Assessment Questionnaire. Arthritis Rheum 1983, 26:1346-1353.

26. Kremer J: The CORRONA database. Ann Rheum Dis 2005, 64:iv37-iv41.

27. Brown AK, Conaghan PG, Karim Z, Quinn MA, lkeda K, Peterfy CG, Hensor E, Wakefield RJ, O'Connor PJ, Emery P: An explanation for the apparent dissociation between clinical remission and continued structural deterioration in rheumatoid arthritis. Arthritis Rheum 2008, 58:2958-2967.

28. Ridker PM, Danielson E, Fonseca FA, Genest J, Gotto AM Jr, Kastelein JJ, Koenig W, Libby P, Lorenzatti AJ, MacFadyen JG, Nordestgaard BG, Shepherd J, Willerson JT, Glynn RJ, JUPITER Study Group: Rosuvastatin to prevent vascular events in men and women with elevated C-reactive protein. N Engl J Med 2008, 359:2195-2207.

29. Konttinen YT, Honkanen VE, Gronblad M, Keinonen M, Santavirta N, Santavirta S: The relation of extraarticular tenderness to inflammatory joint disease and personality in patients with rheumatoid arthritis. J Rheumatol 1992, 19:851-855.

30. Kremer JM, Lee JK: The safety and efficacy of the use of methotrexate in long-term therapy for rheumatoid arthritis. Arthritis Rheum 1986, 29:822-831.

31. Weinblatt ME, Coblyn JS, Fox DA, Fraser PA, Holdsworth DE, Glass DN, Trentham DE: Efficacy of low-dose methotrexate in rheumatoid arthritis. N Engl J Med 1985, 312:818-822.

32. Bentley MJ: Development and evaluation of disease activity measures in rheumatoid arthritis using multi-level mixed modeling and other statistical methodologies: a dissertation. In Dissertation, Doctoral. University of Massachusetts Medical School, Graduate School of Biomedical Sciences; 2010.

33. Maradit-Kremers H, Nicola PJ, Crowson CS, Ballman KV, Gabriel SE: Cardiovascular death in rheumatoid arthritis: a population-based study. Arthritis Rheum 2005, 52:722-732.

\section{doi:10.1186/ar4469}

Cite this article as: Kay et al: Clinical disease activity and acute phase reactant levels are discordant among patients with active rheumatoid arthritis: acute phase reactant levels contribute separately to predicting outcome at one year. Arthritis Research \& Therapy 2014 16:R40.

\section{Submit your next manuscript to BioMed Central and take full advantage of:}

- Convenient online submission

- Thorough peer review

- No space constraints or color figure charges

- Immediate publication on acceptance

- Inclusion in PubMed, CAS, Scopus and Google Scholar

- Research which is freely available for redistribution 